\title{
A GESTÃO DE DOCUMENTOS FRENTE AOS REQUISITOS SIGAD
}

\section{RECORDS MANAGEMENT IN FRONT OF THE SIGAD REQUIREMENTS}

\author{
Virgínia Vendraminia \\ Diana Vilas Boas Souto Aleixob
}

\begin{abstract}
RESUMO
Objetivo: Analisar as funções arquivísticas preconizadas pela gestão de documentos frente aos requisitos do SIGAD. Metodologia: Pesquisa exploratória e descritiva, de abordagem quali-quantitativa, que utiliza procedimentos bibliográficos e documentais. Resultados: Apurou-se que a relevância da tríade das funções de classificação, avaliação e descrição, marca presença embasando direcionamentos presentes nos requisitos do SIGAD. Conclusões: Visualiza-se que o debate e inserção das tecnologias de gestão de conteúdos no ambiente arquivístico pode viabilizar novas estratégias e métodos amparados nas premissas teóricas do campo arquivístico.
\end{abstract}

Descritores: Gestão de Documentos. SIGAD. Gestão de Arquivos. Sistemas de Informação.

\section{INTRODUÇÃO}

Os princípios e práxis arquivísticas incorporados à Gestão de Documentos (GD), são peças-chaves para garantir a eficiência, a eficácia e a qualidade das atividades administrativas, assim como, preservar a memória das organizações.

Cada vez mais o mercado de trabalho do profissional de arquivo está incorporado ao novo ambiente informacional, onde os documentos já nascem digitais. Assim, para assegurar a longevidade das ações que permeiam a criação e a acumulação dos documentos arquivísticos nos ambientes digitais,

a Graduada em Arquivologia pela Universidade Estadual de Londrina (UEL). E-mail: vivi.vendra@gmail.com

b Doutora em Ciência da Informação da Universidade Estadual Paulista (UNESP). Docente do curso de Arquivologia da Universidade Estadual de Londrina (UEL). E-mail: dianavbsouto@gmail.com 
deve-se explorar e otimizar suas aplicações em sistemas e plataformas, para sua adequada "[...] gestão e garantir sua preservação e acesso a longo prazo." (INDOLFO, 2007, p.41).

Destaca-se que a revisão da literatura, propiciou discernir os princípios teóricos-metodológicos que embasam os saberes e fazeres arquivísticos e sequencialmente reconhecer funções da GD face aos requisitos preconizados pelo SIGAD.

Espera-se com a pesquisa propiciar um debate acerca dos conhecimentos essenciais às atividades da Arquivologia, com 0 intuito de estimular profissionais arquivistas a desenvolverem conhecimentos que os capacite ao novo contexto de trabalho.

\section{DA ARQUIVOLOGIA À GESTÃO DE DOCUMENTOS}

Da Antiguidade Clássica à Revolução Francesa, os documentos cumpriram a função de prova e sustentaram o exercício do poder das administrações. Com o fortalecimento da ideia de Estado de Direito impetrado pós Queda da Bastilha, se estabelece o conceito de Soberania Nacional, que reflete na construção dos princípios de responsabilidade, de garantia, eficácia e justiça para administração pública perante a sociedade; desta maneira, os arquivos passam a ser vistos como garantia dos direitos dos cidadãos e como jurisprudência da atuação do Estado (REIS, 2006).

O valor de testemunho para a História atribuído aos documentos, surge apenas em meados do século XIX, quando já consolidada a Revolução Francesa, e a valorização das memórias da humanidade se firmava por influência do Positivismo. No cenário emerge a noção de patrimônio cultural social, o que fez com que os documentos de arquivo passassem a serem vistos, enquanto registros das ações de quem os produziu, como insumo capaz de desvelar e assegurar a memória individual, social e coletiva (INDOLFO, 2007).

$O$ século $X X$, configura-se como um marco de evolução $e$ desenvolvimento científico e tecnológico, consolidando o conceito e a função dos arquivos, que definem-se como "[...] conjunto de documentos produzidos e 
acumulados por um órgão ou entidade, pública ou privada, pessoa ou família, no desempenho de suas atividades, independentemente da natureza do suporte." (BRASIL, 2005, p. 27).

O aumento significativo da produção documental, reflexo do avanço das atividades econômicas e das TIC, desencadeou um acúmulo de grandes massas documentais, e estimulou a busca por novas bases teóricas fazendo surgir de forma pioneira em 1940 nos EUA, o conceito de Records Management (RM), que consolida a prática da Gestão de Documentos (GD) com base no ciclo vital dos documentos (INDOLFO, 2012). No âmago de seu surgimento, a GD apresentava um cunho mais administrativo e econômico do que realmente arquivístico, "[...] uma vez que se tratava, essencialmente, de otimizar o funcionamento da administração, limitando a quantidade de documentos produzidos e o prazo de guarda [...]." (INDOLFO, 2012, p. 15).

No trajeto histórico do desenvolvimento das práticas e embasamentos teóricos em amparo à GD, Philip C. Brooks, na década de 1940, surge como teórico pioneiro a sustentar a ideia do ciclo de vida dos documentos, reflexão que se consolidou em programas de GD (INDOLFO, 2012). Ernst Posner $e$ Theodore R. Schellenberg assumem o papel de difusores do conceito pelo cumprimento das práticas estabelecidas, nos decênios de 1950 a 1960, que proporcionou uma "[...] autêntica revolução na disciplina Arquivística" (INDOLFO, 2012, p. 16).

Ao resguardar as informações nos fluxos de trabalho, os arquivos garantem a preservação da unidade informacional para as comunicações desencadeadas pelo processo, e vinculam as ações que the deram origem aos fluxos operacionais das organizações. Como reflexo, têm a capacidade de embasar tomadas decisões e intervir em "[...] questões como: o que e como devemos produzir, quais os meios disponíveis para fazê-lo e como esses meios podem ser usados [...]." (THOMASSEM, 2006, p. 7).

$\mathrm{Na}$ compreensão da Arquivologia, a GD se configura como um "[...] conjunto de procedimentos e operações técnicas referentes à produção, tramitação, uso, avaliação e arquivamento de documentos em fase corrente e intermediária, visando sua eliminação ou recolhimento." (BRASIL, 2005, p. 
100). Da conceituação destaca-se as três fases básicas da GD: a produção, a utilização e a destinação.

Bernardes e Delatorre (2008) apontam que é atribuição da GD definir as normas e procedimentos técnicos referentes à produção, tramitação, classificação, avaliação, uso e arquivamento dos documentos durante todo o seu ciclo de vida, além de definir seus prazos de guarda e sua destinação final.

A Norma ISO 15489:2001 Information and Documentation - Records Management, foi a primeira Norma ISO na área de documentação e informação que voltou sua atenção aos processos que garantam um sistemático controle da produção, uso, manutenção e eliminação de documentos, para todos os documentos de arquivo, não importando seu suporte ou produtor. A norma dispõe de um conjunto de elementos, requisitos e metodologia que orientam gestores e profissionais responsáveis pela gestão da informação, no desenvolvimento de programas de gestão de documentos (INDOLFO, 2007).

$\mathrm{Na}$ busca por excelência nos objetivos apontados, uma série de atividades são executadas na GD (QUADRO 1).

\section{Quadro 1 - Atividades ligadas a GD}

\begin{tabular}{|c|c|}
\hline Atividade & Função \\
\hline Produção & $\begin{array}{l}\text { Estabelece critérios para elaboração de séries e tipos documentais, assim } \\
\text { como para a implementação de sistemas de organização da informação e para o } \\
\text { emprego de novas tecnologias. }\end{array}$ \\
\hline Utilização & $\begin{array}{l}\text { Abarca todas as atividades do Sistema de Protocolos (recebimento, classificação, } \\
\text { registro, distribuição, tramitação e expedição) e todas as atividades do Sistema de } \\
\text { Arquivos (organização e arquivamento, reprodução, acesso à documentação e a } \\
\text { recuperação de informações), e a gestão de sistemas manuais ou informatizados. }\end{array}$ \\
\hline Destinação & $\begin{array}{l}\text { O acolhimento para a guarda permanente ou o descarte, que devem estar } \\
\text { respaldados pela avaliação de documentos. }\end{array}$ \\
\hline Tramitação & Aprofunda na padronização e no controle do fluxo documental (workflow). \\
\hline $\begin{array}{l}\text { Organização e } \\
\text { Arquivamento }\end{array}$ & $\begin{array}{l}\text { Tem como objetivo prover a organização e o arquivamento segundo os critérios } \\
\text { definidos no Plano de Classificação. }\end{array}$ \\
\hline Reprodução & $\begin{array}{l}\text { Equaciona a reprodução visando a preservação do documento original de guarda } \\
\text { permanente, ou ainda a substituição do documento em papel por microfilme quando } \\
\text { de guarda temporária. }\end{array}$ \\
\hline Classificação & $\begin{array}{l}\text { Resgata o contexto de produção dos documentos, ou seja, a função e a } \\
\text { atividade que determinou a sua produção e identificando os tipos/séries } \\
\text { documentais. }\end{array}$ \\
\hline Avaliação & Demanda multidisciplinar que consiste em identificar valores para os \\
\hline
\end{tabular}




\section{\begin{tabular}{|l|l|}
\hline documentos e analisar seu ciclo de vida, na intenção de estabelecer prazos para \\
sua guarda e destinação (eliminação ou recolhimento)
\end{tabular}}

Fonte: adaptado de Bernardes e Delatorre (2008, p. 9).

O Plano de Classificação de Documentos é o produto da atividade de classificação, recupera o contexto de produção dos documentos de arquivo preservando sua organicidade, função, subfunção e a atividade responsável por sua produção ou salvaguarda. A Tabela de Temporalidade, deriva da atividade de avaliação apoiada pelo plano de classificação, e tem como objetivo definir prazos de guarda para os documentos em razão de seus valores administrativo, fiscal, jurídico-legal, técnico ou histórico, por fim endossa a sua eliminação ou determina a sua guarda permanente (BERNARDES; DELATORRE, 2008).

O Plano de Classificação e a Tabela de Temporalidade, buscam simplificar e racionalizar os procedimentos da atividade, com a intenção de articular maior agilidade e precisão na recuperação dos documentos e das informações, e pautam as diretrizes para a eliminação de documentos, a guarda e a preservação de forma permanente (BERNARDES; DELATORRE, 2008).

Vinculada às atividades de utilização dos arquivos, encontra-se 0 propósito essencial do acesso e da recuperação das informações arquivísticas. Segundo Paes (1997, p. 20), "A função básica do arquivo é tornar disponível as informações contidas no acervo documental sob sua guarda." Assim, progressivamente se desenvolve e se aprimoram métodos e normas para a descrição arquivística, atividade que pode ser definida como "[...] o ato de descrever e representar informações contidas em documentos e/ou fundos de arquivo, gerando instrumentos de pesquisa [...] os quais explicam os documentos de arquivo quanto a sua localização, identificação e gestão [...]." (SOUSA et al., 2006, p. 41). O que dá o caráter relevante à descrição é a potencialidade de suas aplicações viabilizando a compreensão, a manutenção e a recuperação de documentos de arquivo. Sua interferência começa na classificação, passa pela avaliação e se intensifica na criação de instrumentos específicos de controle e acesso dos documentos. 
A Arquivologia contemporânea enfrenta um grande desafio no tocante à representação da informação, para além do esforço empreendido com a normalização da função, os ambientes informacionais digitais, exigem redirecionamentos nas atividades de produção, armazenamento, tratamento, busca, localização, acesso, recuperação e uso das informações, de maneira a desenvolver maior habilidade nas atividades no âmbito da organização, recuperação e compartilhamento da informação na Web.

No contexto da gestão arquivística digital, as organizações padecem com a multiplicidade de tecnologias disponíveis com as quais os princípios e técnicas da gestão de documentos acabam "[...] atropelados em nome da eficiência administrativa e pela falta de visão dos administradores e informáticos sobre o tratamento do documento digital, principalmente documentos digitais permanentes ou de longa guarda." (INNARELLI, 2011, p. 76). Innarelli (2011, p. 76) sublinha que, "[...] os documentos digitais são gerados e incorporados aos sistemas informatizados tendo como ponto de vista seu uso primário e sua operacionalização, com pouca ou nenhuma preocupação em relação à sua gestão e preservação."

A partir da década de 1980, as dificuldades do tratamento do documento eletrônico avolumam-se e surgem inúmeras iniciativas internacionais voltadas a pesquisar pesquisas sobre o uso das TIC nas instituições arquivísticas. Em 1988, sob a iniciativa do CIA ocorre o International Congress on Archives (ICA/CA), o qual foi "[...] pela primeira vez inteiramente dedicado aos novos materiais arquivísticos, foi marcado por amplas discussões sobre definição, conservação e aplicação dos princípios e práticas arquivísticas aos novos materiais." (THOMAZ, 2006, p. 13).

Dollar (2012) compara a profundidade e o alcance da revolução tecnológica à revolução industrial e ao desenvolvimento da escrita. $\mathrm{O}$ autor aponta que as transformações que vivenciadas expõe três imperativos tecnológicos: "[...] a natureza mutável da documentação; a natureza mutável do trabalho e a mudança da própria tecnologia." (DOLLAR, 2012, p. 4). Sob a ótica de tais imperativos, o referido autor questiona a aplicabilidade dos conceitos 
(ordem original, proveniência e preservação), e das práticas arquivísticas básicas no contexto arquivístico digital (DOLLAR, 2012).

O cenário contemporâneo, configura-se com documentos arquivísticos digitais produzidos em larga escala, sendo amplamente viabilizados para acesso por meio das TIC. Logo, torna-se urgente a aplicação de técnicas e o desenvolvimento de políticas efetivas para a manutenção e conservação dos acervos arquivísticos digitais (THOMAZ, 2006).

Em janeiro de 1991, em Washington, EUA, um grupo formado por múltiplas áreas do conhecimento, oportunizado pela National Historical Publications and Records Commission (órgão vinculado à NARA), intitulada Working Meeting on Research Issues in Electronic Records, se reuniu para investigar temas relacionados à questão dos documentos eletrônicos, e propôs uma lista de indagações a de serem respondidas ao longo de uma década (THOMAZ, 2006). Os questionamentos passaram por: Quais processos e dados são imprescindíveis para o gerenciamento de documentos eletrônicos segundo requisitos arquivísticos? Como utilizar dados, diretórios de fontes e metadados como alicerce ao cumprimento dos requisitos arquivísticos? Quais dos requisitos arquivísticos tem sido incorporado no desenvolvimento de sistemas? Como preservar o objeto digital arquivístico a longo prazo? (THOMAZ, 2006).

Embora passadas quase duas décadas, os questionamentos ainda são mais do que oportunos. De fato, são imprescindíveis para a adequação dos afazeres arquivísticos na sociedade contemporânea.

Se é plausível dizer que a Arquivologia se desenvolve em sincronia às sociedades humanas, por consequência, mudanças no contexto tendem a interferir nos posicionamentos teóricos e metodológicos da área. "O que desencadeia a construção de diferentes definições acerca do objeto científico da Arquivologia são as transformações no objeto de trabalho de arquivista, decorrentes do progresso das tecnologias." (SCHMIDT, 2012, p. 293).

A intensidade de absorção das novas ferramentas pela sociedade contemporânea, representou uma mudança de paradigma à área. No esforço 
pela adequação teórica, o campo científico amplia sua teoria e prática com novas abordagens ${ }^{c}$.

Notoriamente, o avanço e a disseminação das TIC têm superado a capacidade temporal de adequação da área. A ausência de consenso, é preocupante à medida que inviabiliza a interoperabilidade das informações, 0 que se apresenta como essencial no mundo globalizado. Dito isso, pode-se compreender a urgência e a necessidade de avanços técnicos e científicos que venham a respaldar o saber e o fazer arquivístico frente à nova realidade social.

Cook (2012) defende que o profissional arquivista deve primeiramente estar apto à pesquisa, alerta a realidade contextual vivenciada e capacitado para interagir com as mudanças impostas pela contemporaneidade, para enfrentar conceitualmente seu impacto sobre a teoria, metodologia e prática arquivísticas.

Possivelmente, a primeira meta a se cumprir na empreitada, passe por uma melhor compreensão das ferramentas disponíveis à implementação dos processos de GD nos ambientes digitais, visto que são com os novos Sistemas de Informação (SI) que os profissionais arquivistas devem interagir com a finalidade de planejar e desenvolver as fases de produção, de utilização e de destinação de seu objeto de trabalho.

\section{SISTEMAS DE INFORMAÇÃO}

Tecnicamente um SI pode ser entendido como "[...] conjunto de componentes inter-relacionados que coletam (ou recuperam), processam, armazenam e distribuem informações destinadas a apoiar a tomada de decisões, a coordenação e o controle de uma organização." (LAUDON, 2010, p. 12).

Segundo Laudon (2010), pode-se delimitar três mecanismos essenciais no SI capazes de prover o controle, a análise e o desenvolvimento nas

\footnotetext{
c A Arquivística Integrada, a Diplomática Arquivística Contemporânea, a Arquivística Funcional ou Pós-moderna e o Records Continuum, são exemplos de propostas teóricas atuais (SCHMIDT, 2012).
} 
organizações, sendo eles: a entrada, método de captura ou coleta de dados internos e externos a organização; o processamento, ou a conversão de dados brutos em elementos significativos; e a saída, a transferência eficiente das informações processadas.

Os SI têm por objetivo assegurar a agilidade e qualidade da informação, que são elementos vitais para as organizações e para seus gestores. Para que se possa utilizar com eficiência as possibilidades ofertadas pelos sistemas, é fundamental uma compreensão lógica dos mecanismos, e a identificação de seu papel perante demandas específicas.

Existe uma diversidade de sistemas disponíveis que se caracterizam pelo tipo de conteúdo que pretendem administrar. Segundo Vieira (2010), os termos mais utilizados na definição dos sistemas são:

a) Sistema de Gestão Documental, caracterizada por se incumbir da criação, aprovação e utilização do documento, em todo seu ciclo de vida.

b) Sistema de Gestão de Documentos de Arquivo, caracterizado como um conjunto de procedimentos e operações técnicas, cuja interação permite a eficiência e a eficácia da gestão arquivística de documentos em todo o seu ciclo de vida, abarcando os processos de captura e preservação como evidência de uma atividade.

c) Sistema de Gestão de Conteúdos Web, caracterizada pela gestão de conteúdo Web em todo o seu ciclo de vida, agregando os processos de publicação na rede.

d) Sistemas de Gestão de Processos de Negócio, caracterizada pela multiplicidade de processos abrangidos. Incorporam a criação, a execução, o monitoramento de variados processos de negócios, envolvendo capital humano e/ou outros sistemas.

e) Sistemas de Gestão de Conteúdos Empresariais (ou corporativo), conhecido pela sigla ECM (Enterprise Content Management), caracterizado por ser um conjunto de tecnologias utilizadas para gerir o ciclo de vida da informação não estruturada que contemplam o gerenciamento de documentos e de conteúdos; 
ferramentas de colaboração; gestão de processos de negócio; entre outros (BAX; OLIVEIRA; BARBOSA, 2011).

Com base nas definições apresentadas, pode-se depreender que 0 Sistema de Gestão de Documentos Arquivísticos é um sistema do gênero dos Sistemas de Gestão de Documentos "[...] que para além de suportar os requisitos gerais de um sistema dessa classe (gestão de conteúdos, em termos gerais), suporta também um conjunto de requisitos específicos impostos pelos objectivos de um arquivo." (VIEIRA, 2010, p. 9).

No intuito de amparar a gestão e preservação dos documentos arquivísticos, assim como sua integração com as ferramentas tecnológicas utilizadas nas organizações, surgiram diferentes propostas de modelos de requisitos para SI. Na presente pesquisa optou-se pela investigação simultânea de dois diferentes modelos de requisitos, sendo o primeiro, oriundo da nação berço da GD amparada pelo conceito do ciclo vital dos documentos e de repercussão internacional, e o outro preconizado no cenário nacional.

No âmbito nacional, a Câmara Técnica de Documentos Eletrônicos (CTDE) do Conselho Nacional de Arquivos (CONARQ) desenvolveu o chamado e-ARQ Brasil, o qual objetiva apontar os "[...] requisitos a serem cumpridos pela organização produtora/recebedora de documentos, pelo sistema de gestão arquivística e pelos próprios documentos, a fim de garantir sua confiabilidade e autenticidade, assim como sua acessibilidade." (CONARQ, 2011, p. 9).

O modelo de requisitos e-ARQ Brasil

[...] especifica todas as atividades e operações técnicas da gestão arquivística de documentos, desde a produção, tramitação, utilização e arquivamento até a sua destinação final. Todas essas atividades poderão ser desempenhadas pelo SIGAD, o qual, tendo sido desenvolvido em conformidade com os requisitos aqui apresentados, conferirá credibilidade à produção e à manutenção de documentos arquivísticos. (CONARQ, 2011, p. 10).

O Sistema Informatizado de Gestão Arquivística de Documentos (SIGAD) pode ser entendido como "[...] um conjunto de procedimentos e operações técnicas, característico do sistema de gestão arquivística de documentos, processado por computador." (CONARQ, 2011, p. 10), o qual 
objetiva a manutenção da relação orgânica dos documentos e a garantia de confiabilidade, de autenticidade e de acesso a longo prazo. É cabível aos sistemas híbridos de documentos, do suporte tradicional ao objeto digital (CONARQ, 2011).

São tópicos presentes em um SIGAD:

[...] captura de documentos, aplicação do plano de classificação, controle de versões, controle sobre os prazos de guarda e destinação, armazenamento seguro e procedimentos que garantam o acesso e a preservação a médio e longo prazo de documentos arquivísticos digitais e não digitais confiáveis e autênticos. (CONARQ, 2011, p. 11).

Entretanto, "O sucesso do SIGAD dependerá, fundamentalmente, da implementação prévia de um programa de gestão arquivística de documentos." (CONARQ, 2011, p. 10). O “[...] e-ARQ Brasil deve ser utilizado para desenvolver um sistema informatizado ou para avaliar um já existente, cuja atividade principal seja a gestão arquivística de documentos" (CONARQ, 2011, p. 12) e seu êxito dependerá "[...] de uma série de decisões, que vão exigir a adoção de uma política arquivística abrangente que não se limita, pura e simplesmente, a selecionar um software ou adaptar um já existente." (CONARQ, 2011, p. 13).

\section{AS FUNÇÕES ARQUIVÍSTICAS FRENTE AOS REQUISITOS SIGAD}

As especificações de requisitos para Sistemas Informatizados de Gestão Arquivística de Documentos (SIGAD) estrutura-se em 14 diferentes capítulos relacionados aos aspectos de funcionalidade que abordam e intitulados como: organização dos documentos arquivísticos; tramitação e fluxo de trabalho; captura; a avaliação e destinação; pesquisa, localização e apresentação dos documentos; segurança; armazenamento; preservação; funções administrativas; usabilidade; interoperabilidade; disponibilidade e por fim, desempenho e a escalabilidade. Os capítulos apontados, por sua vez se desdobram em 44 seções, das quais derivam uma multiplicidade de requisitos classificados como obrigatórios, altamente recomendáveis ou facultativos. 
A análise a seguir (QUADRO 2) teve como foco identificar e quantificar o reflexo e a interação das funções clássicas da Arquivologia (produção, avaliação, aquisição, conservação, classificação, descrição e difusão) em cada uma das 44 seções elencadas. Como critério, buscou-se inferir se o cerne do tópico estaria relacionado a premissas arquivísticas (foco de interesse) ou tratavam-se de direcionamentos voltados especificamente a experiências proporcionadas pelo ambiente digital.

\section{Quadro 2- As funções arquivísticas frente aos requisitos SIGAD}

\begin{tabular}{|c|c|c|}
\hline Requisito & Descrição & Relação \\
\hline \multicolumn{3}{|c|}{ ORGANIZAÇÃO DOS DOCUMENTOS ARQUIVÍSTICOS } \\
\hline $\begin{array}{l}\text { 1.1 Configuração e } \\
\text { administração do plano de } \\
\text { classificação no SIGAD }\end{array}$ & $\begin{array}{l}\text { Um SIGAD tem que incluir e ser compatível com o } \\
\text { plano de classificação do órgão ou entidade. }\end{array}$ & $\begin{array}{l}\text { Classificação e/ou } \\
\text { descrição }\end{array}$ \\
\hline $\begin{array}{l}1.2 \text { Classificação e } \\
\text { metadados das unidades } \\
\text { de arquivamento }\end{array}$ & $\begin{array}{l}\text { Um SIGAD tem que garantir a criação de classes, } \\
\text { subclasses, grupos e subgrupos nos níveis do plano } \\
\text { de classificação de acordo com o método de } \\
\text { codificação adotado. }\end{array}$ & $\begin{array}{l}\text { Classificação e/ou } \\
\text { descrição }\end{array}$ \\
\hline $\begin{array}{l}1.3 \text { Gerenciamento dos } \\
\text { dossiês/processos }\end{array}$ & $\begin{array}{l}\text { Os requisitos desta seção referem-se ao } \\
\text { gerenciamento dos documentos arquivísticos no que } \\
\text { diz respeito a controles de abertura e encerramento } \\
\text { de dossiês/processos e seus respectivos volumes, e } \\
\text { à inclusão de novos documentos nesses } \\
\text { dossiês/processos e seus volumes ou nas pastas } \\
\text { virtuais. }\end{array}$ & $\begin{array}{l}\text { Produção e/ou } \\
\text { avaliação e/ou } \\
\text { aquisição e/ou } \\
\text { classificação e/ou } \\
\text { descrição. }\end{array}$ \\
\hline $\begin{array}{l}\text { 1.4 Requisitos adicionais } \\
\text { para o gerenciamento de } \\
\text { processos }\end{array}$ & $\begin{array}{l}\text { A formação e manutenção de processos no setor } \\
\text { público obedecem a regras específicas, que os } \\
\text { diferenciam dos dossiês e apoiam a preservação de } \\
\text { sua autenticidade. O detalhamento dessas regras } \\
\text { está previsto em normas e legislação específica, } \\
\text { que deverão ser respeitadas pelo órgão ou entidade, } \\
\text { de acordo com sua esfera e âmbito de atuação. Esta } \\
\text { seção inclui requisitos específicos para a gestão } \\
\text { dos processos, aplicáveis caso o SIGAD capture } \\
\text { esse tipo de documento. }\end{array}$ & Especificidade \\
\hline $\begin{array}{l}1.5 \text { Volumes: abertura, } \\
\text { encerramento e } \\
\text { metadados }\end{array}$ & $\begin{array}{l}\text { Em alguns casos os dossiês/processos são } \\
\text { compartimentados em volumes ou partes, de acordo } \\
\text { com normas e instruções estabelecidas. Essa divisão } \\
\text { não se baseia no conteúdo intelectual dos } \\
\text { dossiês/processos, mas em outros critérios, como } \\
\text { dimensão, número de documentos, períodos de } \\
\text { tempo etc. A prática tem como objetivo facilitar o } \\
\text { gerenciamento físico dos dossiês/processos. Os } \\
\text { requisitos desta seção referem-se à utilização de } \\
\text { volumes para subdividir dossiês/processos. }\end{array}$ & $\begin{array}{l}\text { Produção e/ou } \\
\text { conservação e/ou } \\
\text { difusão e/ou } \\
\text { descrição }\end{array}$ \\
\hline $\begin{array}{l}1.6 \text { Gerenciamento de } \\
\text { documentos e } \\
\text { processos/dossiês }\end{array}$ & $\begin{array}{l}\text { Um SIGAD deve registrar os documentos ou } \\
\text { dossiês/processos convencionais, que devem ser } \\
\text { classificados com base no mesmo plano de }\end{array}$ & $\begin{array}{l}\text { Classificação e/ou } \\
\text { descrição }\end{array}$ \\
\hline
\end{tabular}




\begin{tabular}{|c|c|c|}
\hline $\begin{array}{l}\text { arquivísticos } \\
\text { convencionais e híbridos }\end{array}$ & $\begin{array}{l}\text { classificação usado para os digitais, e ainda } \\
\text { possibilitar a gestão de documentos ou } \\
\text { dossiês/processos híbridos. Os documentos ou } \\
\text { dossiês/processos híbridos são formados por uma } \\
\text { parte digital e outra convencional. }\end{array}$ & \\
\hline \multicolumn{3}{|c|}{ TRAMITAÇÃO E FLUXO DE TRABALHO } \\
\hline $\begin{array}{l}2.1 \text { Controle do fluxo de } \\
\text { trabalho }\end{array}$ & $\begin{array}{l}\text { Os requisitos desta seção tratam apenas dos casos } \\
\text { em que o SIGAD inclui recursos de automação de } \\
\text { fluxo de trabalho (workflow). Eles abrangem } \\
\text { funções para controle do fluxo de trabalho e } \\
\text { atribuição de metadados para registro da tramitação } \\
\text { dos documentos, incluindo-se o status do documento } \\
\text { (minuta, original ou cópia). }\end{array}$ & Especificidade \\
\hline $\begin{array}{l}2.2 \text { Controle de versões e } \\
\text { do status do documento }\end{array}$ & $\begin{array}{l}\text { Um SIGAD tem que ser capaz de, por meio de seu recurso } \\
\text { de fluxo de trabalho, estabelecer o status do documento, } \\
\text { isto é, se é uma minuta, original ou cópia. No caso dos } \\
\text { documentos digitais, esse status é estabelecido de acordo } \\
\text { com a rota do documento no SIGAD. }\end{array}$ & Especificidade \\
\hline \multicolumn{3}{|c|}{ CAPTURA } \\
\hline 3.1 Procedimentos gerais & $\begin{array}{l}\text { A captura consiste em declarar um documento como } \\
\text { documento arquivístico ao incorporá-lo num SIGAD por } \\
\text { meio das ações de registro, classificação, indexação, } \\
\text { atribuição de metadados e arquivamento. }\end{array}$ & $\begin{array}{l}\text { Produção e/ou } \\
\text { aquisição e/ou } \\
\text { classificação e/ou } \\
\text { descrição }\end{array}$ \\
\hline 3.2 Captura em lote & $\begin{array}{l}\text { Um SIGAD tem que proporcionar a captura em lote } \\
\text { de documentos gerados por outros sistemas }\end{array}$ & Especificidade \\
\hline $\begin{array}{l}\text { 3.3 Captura de } \\
\text { mensagens de correio } \\
\text { eletrônico }\end{array}$ & $\begin{array}{l}\text { O correio eletrônico é um sistema usado para criar, } \\
\text { transmitir e receber mensagens eletrônicas e outros } \\
\text { documentos digitais por meio de redes de } \\
\text { computadores. As características do correio } \\
\text { eletrônico podem dificultar o seu gerenciamento. }\end{array}$ & Especificidade \\
\hline $\begin{array}{l}\text { 3.4 Captura de } \\
\text { documentos } \\
\text { convencionais ou híbridos }\end{array}$ & $\begin{array}{l}\text { O programa de gestão arquivística de documentos } \\
\text { de um órgão ou entidade é único para documentos } \\
\text { convencionais, digitais e híbridos. [...] A captura do } \\
\text { documento convencional será realizada pelo SIGAD } \\
\text { por meio das atividades de registro, classificação e } \\
\text { indexação. O arquivamento será feito da forma } \\
\text { apropriada ao suporte, formato e tipo de documento. }\end{array}$ & $\begin{array}{l}\text { Produção e/ou } \\
\text { aquisção e/ou } \\
\text { classificação e/ou } \\
\text { descrição }\end{array}$ \\
\hline $\begin{array}{l}\text { 3.5 Formato de arquivo e } \\
\text { estrutura dos documentos } \\
\text { a serem capturados }\end{array}$ & $\begin{array}{l}\text { Órgãos e entidades precisam capturar uma gama } \\
\text { diversificada de documentos com formatos de } \\
\text { arquivo e estruturas diferentes. Os requisitos } \\
\text { técnicos para a captura variam de acordo com a } \\
\text { complexidade dos documentos. }\end{array}$ & Especificidade \\
\hline $\begin{array}{l}\text { 3.6 Estrutura dos } \\
\text { procedimentos de gestão }\end{array}$ & $\begin{array}{l}\text { A gestão arquivística de documentos digitais prevê o } \\
\text { estabelecimento de três domínios no ambiente eletrônico: } \\
\text { espaço individual, espaço do grupo e espaço geral. }\end{array}$ & Especificidade \\
\hline \multicolumn{3}{|c|}{ AVALIAÇÃO E DESTINAÇÃO } \\
\hline $\begin{array}{l}\text { 4.1 Configuração da tabela } \\
\text { de temporalidade e } \\
\text { destinação de documentos }\end{array}$ & $\begin{array}{l}\text { Estes requisitos referem-se à criação e manutenção } \\
\text { de tabelas de temporalidade em um SIGAD. }\end{array}$ & $\begin{array}{l}\text { Avaliação e/ou } \\
\text { Descrição }\end{array}$ \\
\hline
\end{tabular}




\begin{tabular}{|c|c|c|}
\hline $\begin{array}{l}\text { 4.2 Aplicação da tabela } \\
\text { de temporalidade e } \\
\text { destinação de } \\
\text { documentos }\end{array}$ & $\begin{array}{l}\text { Estes requisitos referem-se à aplicação da tabela de } \\
\text { temporalidade e destinação de documentos, ou seja, } \\
\text { aos procedimentos de controle e verificação dos prazos e } \\
\text { da destinação previstos, antes de se proceder às ações } \\
\text { de destinação propriamente ditas. }\end{array}$ & $\begin{array}{l}\text { Avaliação e/ou } \\
\text { descrição }\end{array}$ \\
\hline $\begin{array}{l}\text { 4.3 Exportação de } \\
\text { documentos }\end{array}$ & $\begin{array}{l}\text { Um SIGAD deve ter capacidade de exportar } \\
\text { documentos para apoiar as ações de } \\
\text { transferência e recolhimento de documentos, ou } \\
\text { ainda para realizar uma migração ou enviar uma } \\
\text { cópia para outro local ou sistema. }\end{array}$ & Especificidade \\
\hline 4.4 Eliminação & $\begin{array}{l}\text { A eliminação de documentos arquivísticos deve ser } \\
\text { realizada de acordo com o previsto na tabela de } \\
\text { temporalidade e destinação de documentos, após a } \\
\text { avaliação dos documentos e de acordo com a } \\
\text { legislação vigente. }\end{array}$ & $\begin{array}{l}\text { Avaliação e/ou } \\
\text { Descrição }\end{array}$ \\
\hline $\begin{array}{l}\text { 4.5 Avaliação e } \\
\text { destinação de } \\
\text { documentos arquivísticos } \\
\text { convencionais e híbridos }\end{array}$ & $\begin{array}{l}\text { Os documentos arquivísticos convencionais e os } \\
\text { híbridos gerenciados pelo SIGAD devem ter os } \\
\text { procedimentos de avaliação e destinação } \\
\text { controlados pelo SIGAD, da mesma forma que os } \\
\text { documentos digitais. }\end{array}$ & $\begin{array}{l}\text { Avaliação e/ou } \\
\text { Descrição }\end{array}$ \\
\hline \multicolumn{3}{|c|}{ PESQUISA, LOCALIZAÇÃO E APRESENTAÇÃO DOS DOCUMENTOS } \\
\hline 5.1 Aspectos gerais & $\begin{array}{l}\text { Um SIGAD precisa prover funcionalidades para } \\
\text { pesquisa, localização e apresentação dos } \\
\text { documentos arquivísticos com o objetivo de permitir } \\
\text { o acesso a eles. Todas essas funcionalidades têm de } \\
\text { ser submetidas aos controles de acesso descritos na } \\
\text { seção } 6 \text { - Segurança. }\end{array}$ & $\begin{array}{l}\text { Classificação e/ou } \\
\text { descrição e/ou } \\
\text { difusão }\end{array}$ \\
\hline $\begin{array}{l}5.2 \text { Pesquisa e } \\
\text { localização }\end{array}$ & $\begin{array}{l}\text { A pesquisa é o processo de identificação de } \\
\text { documentos arquivísticos por meio de parâmetros } \\
\text { definidos pelo usuário com o objetivo de confirmar, } \\
\text { localizar e recuperar esses documentos, bem como } \\
\text { seus respectivos metadados. }\end{array}$ & $\begin{array}{l}\text { Classificação e/ou } \\
\text { descrição e/ou } \\
\text { difusão }\end{array}$ \\
\hline $\begin{array}{l}\text { 5.3 Apresentação: } \\
\text { visualização, impressão, } \\
\text { emissão de som }\end{array}$ & $\begin{array}{l}\text { Um SIGAD pode conter documentos arquivísticos } \\
\text { com os mais diversos formatos e estruturas, e deve } \\
\text { ter a capacidade de apresentar esses } \\
\text { documentos ao usuário sem adulterá-los, seja } \\
\text { exibindo-os na tela do computador, imprimindo } \\
\text { ou emitindo som. O sistema deve informar os } \\
\text { programas (softwares) adicionais necessários e a } \\
\text { configuração adequada, como, por exemplo, plug-in } \\
\text { e configuração de navegador. }\end{array}$ & Especificidade \\
\hline \multicolumn{3}{|c|}{ SEGURANÇA } \\
\hline 6.1 Cópias de segurança & $\begin{array}{l}\text { As cópias de segurança têm por objetivo prevenir a } \\
\text { perda de informações e garantir a disponibilidade do } \\
\text { sistema. Os procedimentos de backup devem ser } \\
\text { feitos regularmente e pelo menos uma cópia deve } \\
\text { ser armazenada, preferencialmente off-site. }\end{array}$ & Especificidade \\
\hline 6.2 Controle de acesso & $\begin{array}{l}\text { Esta seção trata dos requisitos de identificação e } \\
\text { autenticação de usuários, controle de acesso } \\
\text { baseado em grupos de usuários e em papéis de } \\
\text { usuários, bem como dos requisitos comuns a } \\
\text { qualquer tipo de controle de acesso. }\end{array}$ & Especificidade \\
\hline
\end{tabular}




\begin{tabular}{|c|c|c|}
\hline $\begin{array}{l}6.3 \text { Classificação da } \\
\text { informação quanto ao } \\
\text { grau de sigilo e } \\
\text { restrição de acesso à } \\
\text { informação sensível }\end{array}$ & $\begin{array}{l}\text { Os requisitos desta seção são aplicáveis a qualquer } \\
\text { organização para condução de suas funções e } \\
\text { atividades, independentemente do modelo de } \\
\text { controle de acesso adotado, de acordo com a política } \\
\text { de segurança. }\end{array}$ & $\begin{array}{l}\text { Classificação e/ou } \\
\text { avaliação e/ou } \\
\text { descrição }\end{array}$ \\
\hline 6.4 Trilhas de auditoria & $\begin{array}{l}\text { A trilha de auditoria consiste num histórico de todas as } \\
\text { intervenções, ou tentativas de intervenção, feitas no } \\
\text { documento e no próprio SIGAD. Nesse sentido, é também } \\
\text { um metadado sobre os documentos arquivísticos digitais e } \\
\text { informa sobre sua autenticidade. }\end{array}$ & Especificidade \\
\hline 6.5 Assinaturas digitais & $\begin{array}{l}\text { Assinatura digital é uma sequência de bits que usa } \\
\text { algoritmos específicos, chaves criptográficas e } \\
\text { certificados digitais para autenticar a identidade do } \\
\text { assinante e confirmar a integridade de um } \\
\text { documento. Certificação digital é uma técnica, } \\
\text { baseada em uma infraestrutura de chaves públicas, } \\
\text { de garantia da validade de assinaturas digitais. }\end{array}$ & Especificidade \\
\hline 6.6 Criptografia & $\begin{array}{l}\text { Criptografia é um método de codificação de } \\
\text { objetos digitais segundo um código secreto (chave), } \\
\text { de modo que não possam ser apresentados de forma } \\
\text { legível ou inteligível por uma aplicação e somente } \\
\text { usuários autorizados sejam capazes de restabelecer } \\
\text { sua forma original }\end{array}$ & Especificidade \\
\hline 6.7 Marcas d'água digitais & $\begin{array}{l}\text { Marcas d'água servem para marcar uma imagem } \\
\text { digital com informação sobre sua proveniência e } \\
\text { características, e são utilizadas para proteger a } \\
\text { propriedade intelectual. }\end{array}$ & Especificidade \\
\hline $\begin{array}{l}\text { 6.8 Acompanhamento de } \\
\text { transferência }\end{array}$ & $\begin{array}{l}\text { Durante seu ciclo de vida, os documentos } \\
\text { arquivísticos digitais e seus respectivos metadados } \\
\text { podem ser transferidos de uma mídia de suporte, ou } \\
\text { de um local, para outro, à medida que seu uso } \\
\text { decresce e/ou se modifica. }\end{array}$ & $\begin{array}{l}\text { Avaliação e/ou } \\
\text { descrição }\end{array}$ \\
\hline 6.9 Autoproteção & $\begin{array}{l}\text { Num ambiente digital, a autoproteção consiste na } \\
\text { capacidade do sistema de computação de } \\
\text { verificar a integridade de programas e dados de } \\
\text { controle como uma medida de proteção inicial. }\end{array}$ & Especificidade \\
\hline $\begin{array}{l}6.10 \text { Alterar, apagar e } \\
\text { truncar documentos } \\
\text { arquivísticos digitais }\end{array}$ & $\begin{array}{l}\text { A ação de eliminar pode ter um dos significados a } \\
\text { seguir: } \\
\text { - Eliminação definitiva; } \\
\text { - Retenção, acompanhada de anotação nos } \\
\text { metadados do documento arquivístico, } \\
\text { informando que ele não está mais sob o } \\
\text { controle da gestão de documentos } \\
\text { arquivísticos. }\end{array}$ & Especificidade \\
\hline \multicolumn{3}{|c|}{ ARMAZENAMENTO } \\
\hline 7.1 Durabilidade & $\begin{array}{l}\text { Os dispositivos de armazenamento de um SIGAD } \\
\text { e os documentos neles armazenados devem estar } \\
\text { sujeitos a ações de preservação que garantam sua } \\
\text { conservação de longo prazo. }\end{array}$ & Especificidade \\
\hline 7.2 Capacidade & $\begin{array}{l}\text { Um SIGAD deve garantir escalabilidade no } \\
\text { armazenamento, permitindo a expansão ilimitada dos } \\
\text { dispositivos de armazenamento. }\end{array}$ & Especificidade \\
\hline
\end{tabular}




\begin{tabular}{|c|c|c|}
\hline $\begin{array}{l}7.3 \text { Efetividade de } \\
\text { armazenamento }\end{array}$ & Dispositivos de armazenamento & Especificidade \\
\hline \multicolumn{3}{|c|}{ PRESERVAÇÃO } \\
\hline 8.1 Aspectos físicos & $\begin{array}{l}\text { Ressalte-se que as características desses } \\
\text { documentos demandam atenção específica, } \\
\text { sobretudo em relação àqueles que serão mantidos } \\
\text { por mais de cinco anos, o que, nesse contexto, já se } \\
\text { considera preservação de longo prazo. A } \\
\text { degradação do suporte [...] }\end{array}$ & $\begin{array}{l}\text { Conservação e/ou } \\
\text { Descrição }\end{array}$ \\
\hline 8.2 Aspectos lógicos & $\begin{array}{l}\text { [...] obsolescência tecnológica são os principais } \\
\text { fatores de comprometimento da preservação dos } \\
\text { documentos digitais, uma vez que ameaçam sua } \\
\text { autenticidade, integridade e acessibilidade. }\end{array}$ & Especificidade \\
\hline 8.3 Aspectos gerais & $\begin{array}{l}\text { Um SIGAD deve utilizar suportes de armazenamento } \\
\text { e recursos de hardware e software que sejam } \\
\text { maduros, estáveis no mercado e amplamente } \\
\text { disponíveis. }\end{array}$ & Especificidade \\
\hline \multicolumn{3}{|c|}{ FUNÇÕES ADMINISTRATIVAS } \\
\hline $\begin{array}{l}9 \text { Funções } \\
\text { administrativas }\end{array}$ & $\begin{array}{l}\text { Um SIGAD tem que permitir que os administradores, de } \\
\text { maneira controlada e sem esforço excessivo, recuperem, } \\
\text { visualizem e reconfigurem os parâmetros do sistema e } \\
\text { os atributos dos usuários. }\end{array}$ & Especificidade \\
\hline \multicolumn{3}{|c|}{ CONFORMIDADE COM A LEGISLAÇÃO E REGULAMENTAÇÕES } \\
\hline $\begin{array}{l}10 \text { Conformidade } \\
\text { com a legislação e } \\
\text { regulamentações }\end{array}$ & $\begin{array}{l}\text { Um SIGAD tem que cumprir a legislação e as } \\
\text { regulamentações vigentes. Setores de atividades } \\
\text { distintos apresentam requisitos legislativos e } \\
\text { regulamentares diferenciados. }\end{array}$ & Especificidade \\
\hline \multicolumn{3}{|c|}{ USABILIDADE } \\
\hline 11 Usabilidade & $\begin{array}{l}\text { Um sistema de software com boa usabilidade } \\
\text { deve apoiar a realização de tarefas simples, diretas e } \\
\text { objetivas, que garantam as metas de produtividade e } \\
\text { qualidade de trabalho do usuário. }\end{array}$ & Especificidade \\
\hline \multicolumn{3}{|c|}{ INTEROPERABILIDADE } \\
\hline 12 Interoperabilidade & $\begin{array}{l}\text { Esta seção estabelece requisitos mínimos para que } \\
\text { um SIGAD possa interoperar com outros sistemas de } \\
\text { informação, inclusive sistemas legados, respeitando } \\
\text { normas de segurança de acordo com padrões } \\
\text { abertos de interoperabilidade. }\end{array}$ & Especificidade \\
\hline \multicolumn{3}{|c|}{ DISPONIBILIDADE } \\
\hline 13 Disponibilidade & $\begin{array}{l}\text { Requisitos de disponibilidade descrevem as } \\
\text { exigências mínimas sobre prontidão de } \\
\text { atendimento de um sistema. Os requisitos de } \\
\text { disponibilidade devem ser especificados pelo } \\
\text { administrador do SIGAD de acordo com o nível de } \\
\text { serviço a ser fornecido. }\end{array}$ & Especificidade \\
\hline \multicolumn{3}{|c|}{ DESEMPENHO E ESCALABILIDADE } \\
\hline
\end{tabular}




\begin{tabular}{|l|l|l|}
\hline 14 Desempenho e & $\begin{array}{l}\text { Os requisitos de desempenho enfocam a eficiência } \\
\text { escalabilidade }\end{array}$ & Especificidade \\
expectativas quanto ao tempo de resposta. [...] Em & \\
um SIGAD, entende-se escalabilidade como a \\
capacidade de um sistema responder a um \\
aumento do número de usuários e do volume de \\
documentos arquivísticos, mantendo o \\
desempenho de suas respostas.
\end{tabular}

Fonte: Elaboração própria.

A análise do Quadro 1, de caráter quali-quantitativo, deu-se por meio de duas etapas. Inicialmente, buscou-se aferir dentro das seções de requisitos SIGAD, a proporção de tópicos voltados a especificidades típicas dos sistemas de informações e a proporção dos tópicos passíveis de inferências junto as sete funções arquivísticas (Gráfico 1).

\section{Gráfico 1 - Proporção de seções que se relacionam com as funções arquivísticas}

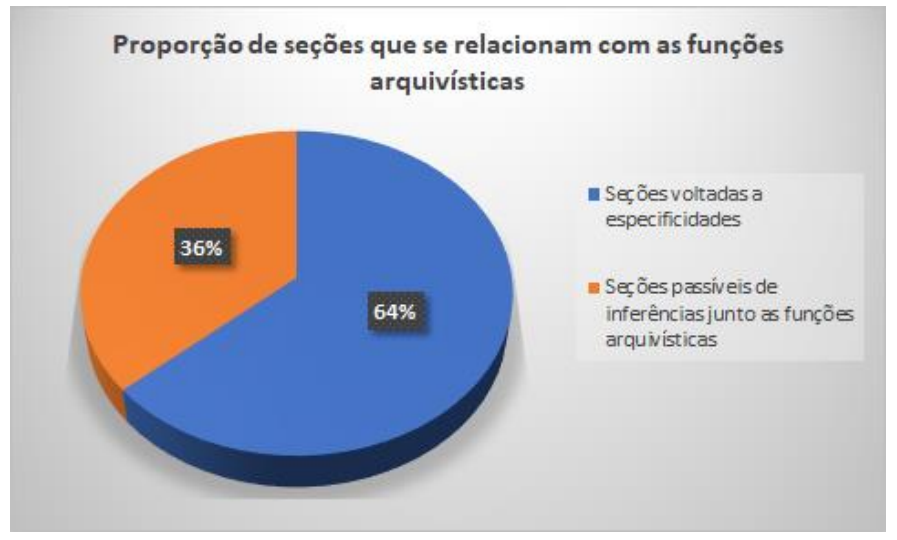

Fonte: Elaboração própria.

A análise apontou um índice de $63,63 \%$ de seções voltadas às especificidades do ambiente digital e 36,36\% de seções relacionadas às funções arquivísticas.

Como prosseguimento investigou-se dentro das seções relacionadas às funções arquivísticas, quais e quantas das sete funções arquivísticas estavam presentes em cada um dos tópicos. (GRÁFICO 2). 


\section{Gráfico 2 - Funções arquivísticas percebidas nas seleções selecionadas}

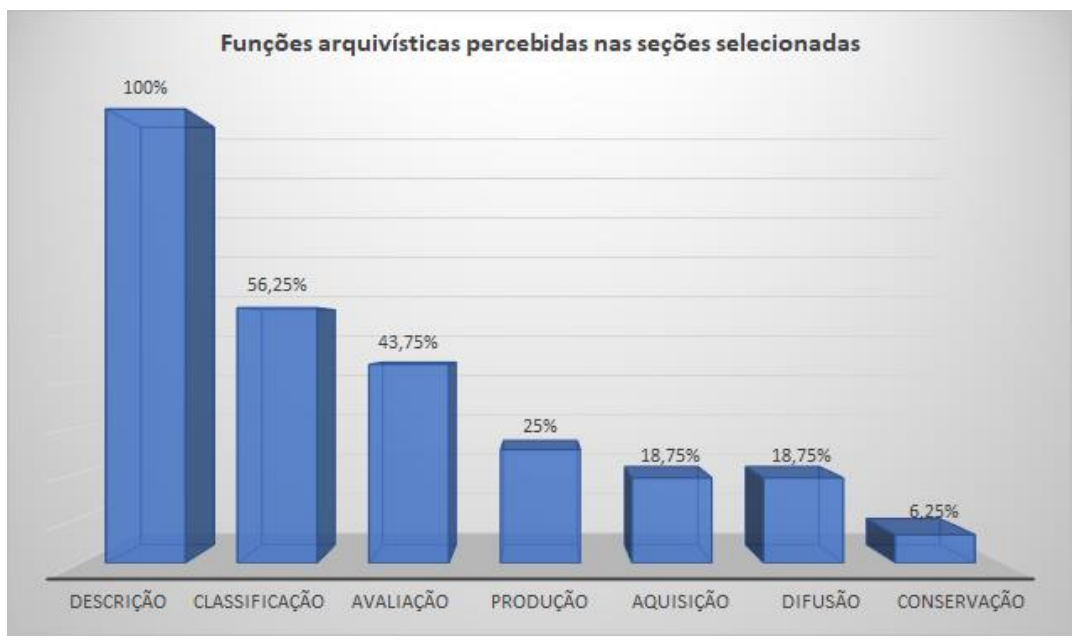

Fonte: Elaboração própria.

As inferências associadas à função de descrição surgiram em 100\% dos casos, seguida por $56,25 \%$ para a classificação, $43,75 \%$ para avaliação, $25 \%$ para a produção, $18,75 \%$ para a aquisição, $18,75 \%$ para a difusão e $6,25 \%$ para a conservação.

A análise das seções de requisitos do SIGAD corroborou com os resultados obtidos a partir do aprofundamento teórico obtido por meio da revisão de literatura, demonstrando que a relevância da tríade das funções de classificação, avaliação e descrição, marca sua presença embasando muitos dos direcionamentos apresentados pelo modelo de requisitos abordado. Logo, entende-se que pouco mais de $1 / 3$ das seções de requisitos propostos pelo SIGAD estão voltados à inferências advindas da visão teórica da tradição e apontam o "coração das práticas arquivísticas". O dado nos leva a ponderar que o cerne da arquivologia custodial permanece predominante, mas em contrapartida, $2 / 3$ dos requisitos baseiam-se em conhecimentos distintos do núcleo da teoria observada, o que evidencia rupturas face a arquivologia póscustodial e possivelmente uma demanda por adequação da fundamentação teórica para área. 


\section{REFERÊNCIAS}

ARQUIVO NACIONAL (Brasil). Dicionário brasileiro de terminologia arquivística. Rio de Janeiro: Arquivo Nacional, 2005. p. 232 (Publicações Técnicas; 51). Disponível em:

http://www.arquivonacional.gov.br/images/pdf/Dicion_Term_Arquiv.pdf. Acesso em: 26 abr. 2021.

ARQUIVO NACIONAL (Brasil). Gestão de documentos: curso de capacitação para os integrantes do Sistema de Gestão de Documentos de Arquivo - SIGA, da administração pública federal. Rio de Janeiro: Arquivo Nacional, 2011. (Publicações Técnicas; n. 55). Disponível em: http://www.siga.arquivonacional.gov.br/images/cursos_capacitacao/Apostila_ge stao_documentos_2015.pdf. Acesso em: 26 abr. 2021.

BAX, M. P.; OLIVEIRA, J. L. R.; BARBOSA, D. M. Gerenciamento de Documentos Eletrônicos: Estudo de Caso com o Sistema de Gestão de Conteúdo Plone. Perspectivas em Gestão \& Conhecimento, v. 1, n. 2, p. 166-190, 2011.

BERNARDES, I. P.; DELATORRE, H. Gestão Documental Aplicada. São Paulo: Arquivo Público do Estado de São Paulo, 2008.

CONSELHO NACIONAL DE ARQUIVOS (Brasil). Câmara Técnica de Documentos Eletrônicos. e-ARQ Brasil: Modelo de Requisitos para Sistemas Informatizados de Gestão Arquivística de Documentos. Rio de Janeiro: Arquivo Nacional, 2011. Disponível em:

http://www.siga.arquivonacional.gov.br/images/publicacoes/e-arq.pdf. Acesso em: 26 abr. 2021.

COOK, T. A ciência arquivística e o pós-modernismo: novas formulações para conceitos antigos. InCID: Revista de Ciência da Informação e Documentação, v. 3, n. 2, p. 3-27, 2012.

DOLLAR, C. M. O impacto das tecnologias de informação sobre princípios e práticas de arquivos: algumas considerações. Revista Acervo, v. 7, n. 1-2, p. 3-38, 2012.

DURANTI, L. Registros documentais contemporâneos como provas de ação. Revista Estudos Históricos, Rio de Janeiro, v. 7, n. 13, p. 49-64, jul. 1994.

INDOLFO, A. C. Avaliação de documentos de arquivo: atividade estratégica para a gestão de documentos. Revista do Arquivo Geral da Cidade do Rio de Janeiro. Rio de Janeiro, v. 6, p. 13-37, 2012. 
INDOLFO, A. C. Gestão de documentos: uma renovação epistemológica no universo da arquivologia. Arquivística. net, Rio de janeiro, v. 3, n. 2, p. 28-60, 2007.

INNARELLI, H. C. Preservação digital: a influência da gestão dos documentos digitais na preservação da informação e da cultura. RDBCI: Revista Digital de Biblioteconomia e Ciência da Informação, v. 9, n. 1, p. 72-87, 2011.

LAUDON, K. Sistemas de informação gerenciais. Trad. Luciana do Amaral Teixeira. 9. ed. São Paulo: Pearson Prentice Hall, 2010.

PAES, M. L. Arquivo: teoria e prática. Rio de Janeiro: Fundação Getúlio Vargas, 1997.

REIS, Luís. O arquivo e arquivística evolução histórica. Biblios: Revista electrónica de bibliotecología, archivología y museología, n. 24, p. 5, 2006.

SCHMIDT, C. M. S. Arquivologia e a construção do seu objeto científico: concepções, trajetórias, contextualizações. 2012. 320 f. Tese (Doutorado em Ciência da Informação) - Universidade de São Paulo, São Paulo, 2012. Disponível em: http://www.teses.usp.br/teses/disponiveis/27/27151/tde02072013-170328/en.php. Acesso em: 26 abr. 2021.

THOMASSEM, T. Uma primeira introdução à arquivologia. Arquivo \& Administração. Rio de Janeiro, v. 5, n. 1, p. 5-16, 2006.

THOMAZ, K. P. Gestão e preservação de documentos eletrônicos de arquivo: revisão de literatura-parte 2. Arquivística. net, v. 2, n. 1, p. 114-131, 2006.

VIEIRA, R. SmartDocs-Inovação em Gestão Documental. Lisboa: Instituto Superior Técnico da Universidade Técnica de Lisboa, 2010. Disponível em: https://fenix.tecnico.ulisboa.pt/downloadFile/395142117361/[Disserta\%E7\%E3o \%20Mestrado][55406]\%20Ricardo\%20Vieira.pdf. Acesso em: 26 abr. 2021.

\title{
RECORDS MANAGEMENT IN FRONT OF THE SIGAD REQUIREMENTS
}

\begin{abstract}
Objective: To analyze the archival functions recommended by document management in view of the requirements of SIGAD. Methodology: Exploratory and descriptive research, with a qualitative and quantitative approach, using bibliographic and documentary procedures. Results: It was found that the relevance of the triad of classification, evaluation and description functions is present, supporting the guidelines present in the requirements of SIGAD. Conclusions: It can be seen that the debate and insertion of content management technologies in the archival environment can enable new strategies and methods based on the theoretical premises of the archival
\end{abstract}


field.

Descriptors: Records Management. SIGAD. Management of archives. Information systems.

\section{GESTIÓN DE DOCUMENTOS ANTE LOS REQUISITOS DE SIGAD}

\section{RESUMEN}

Objetivo: Analizar las funciones de archivo recomendadas por la gestión documental ante los requerimientos de la SIGAD. Metodología: Investigación exploratoria y descriptiva, con enfoque cualitativo y cuantitativo, utilizando procedimientos bibliográficos y documentales. Resultados: Se encontró que la relevancia de la tríada de funciones de clasificación, evaluación y descripción está presente, sustentando los lineamientos presentes en los requisitos de la SIGAD. Conclusiones: Se puede apreciar que el debate y la inserción de tecnologías de gestión de contenidos en el entorno archivístico pueden posibilitar nuevas estrategias y métodos basados en las premisas teóricas del campo archivístico.

Descriptores: Gestión de documentos. SIGAD. Gestión de archivos. Sistemas de información.

Recebido em:19.04.2021

Aceito em: 30.04 .2021 